\title{
Joule Heating Effects on MHD Natural Convection Flows in Presence of Pressure Stress Work and Viscous Dissipation from a Horizontal Circular Cylinder
}

\author{
A. S. Bhuiyan ${ }^{1 \dagger}$, N. H. M. A. Azim² and M. K. Chowdhury ${ }^{3}$ \\ ${ }^{1}$ Department of Mathematics, Brock University, St. Catharines, Ontario, L2S 3A1, Canada \\ ${ }^{2}$ School of Business Studies, Southeast University, Dhaka-1213, Bangladesh \\ ${ }^{3}$ Department of Mathematics, Bangladesh University of Engineering and Technology, Dhaka, Bangladesh
}

†Corresponding Author Email: bd_abdussamad@yahoo.com

(Received January 16, 2011; accepted March 27, 2013)

\begin{abstract}
The effects of joule heating on MHD natural convection flow from a horizontal circular cylinder along the outer surface from the lower stagnation point to the upper stagnation point in presence of pressure stress work and viscous dissipation is investigated. The results have been obtained by transforming the governing boundary layer equations into a system of non-dimensional equations and by applying implicit finite difference method together with Newton's linearization approximation. Numerical results for different values of the magnetic parameter, joule heating parameter and Prandtl number have been obtained. The velocity profiles, temperature distributions, skin friction co-efficient and the rate of heat transfer have been presented graphically for the effects of the aforementioned parameters. Results are compared with previous investigation.
\end{abstract}

Keywords: Natural convection, Viscous dissipation, Pressure stress work, MHD, Joule heating.

\section{NOMENCLATURE}

$C f_{x} \quad$ local skin friction coefficient

$c_{p} \quad$ specific heat at constant pressure

$f \quad$ dimensionless stream function

Gr local Grashof number

$g \quad$ acceleration due to gravity

$J \quad$ joule heating parameter

M magnetic parameter

$N u_{x} \quad$ local Nusselt number coefficient

Pr Prandtl number

$T_{w} \quad$ temperature at the surface of the cylinder

$T$ temperature of the ambient fluid

$T \quad$ temperature of the fluid in the boundary

$u, v \quad$ the dimensionless $\mathrm{x}$ and $\mathrm{y}$ component velocity

$\bar{u}, \bar{v}$ the dimensional $\bar{x}$ and $\bar{y}$ component of the velocity

$\begin{array}{ll}x, y & \text { dimensionless Cartesian coordinates } \\ \bar{x}, \bar{y} & \text { dimensional Cartesian coordinates } \\ v & \text { kinematics viscosity } \\ \mu & \text { viscosity of the fluid } \\ \theta & \text { dimensionless temperature function } \\ \lambda & \text { viscous dissipation parameter } \\ \varepsilon & \text { pressure stress work parameter } \\ \beta & \text { co-efficient of thermal expansion } \\ \beta_{0} & \text { magnetic field strength } \\ \Psi & \text { stream function } \\ \rho & \text { density of the fluid } \\ \sigma & \text { electric conduction }\end{array}$

of the

$$
\text { e }
$$




\section{INTRODUCTION}

The influence and importance of viscous dissipation effects in free convection flows have been examined by Gebhar (1962). Zakerullah (1972) has been investigated the viscous dissipation and pressure work effects in axisymmetric natural convection flows. Ackroyd (1974) studied the stress work effects in laminar flat plate natural convection flow. Takhar and Soundalgekar (1980) have studied the effects of viscous and joule heating on the problem posed by Sparrow and Cess (1961), using the series expansion method of Gebhart. But they investigated generally not in a particular case of study. Natural convection flow from a horizontal cylinder due to thermal buoyancy was analyzed by a number of researchers Merkin et al. (1988), Kuehn et al. (1980) and Wang et al. (1990). Joshi and Gebhart (1981) have shown the effect of pressure stress work and viscous dissipation in some natural convection flows. Effects of pressure stress work and viscous dissipation in natural convection flow along a vertical flat plate with heat conduction have been investigated by Alam et al. (2006). Recently, Hye et al. (2007) have considered the effects of heat and mass transfer on natural convection flows across an isothermal horizontal circular cylinder with chemical reaction.

MHD flow and heat transfer process are now an important research area due to its potential application in engineering and industrial fields. A considerable amount of research has been done in this field. Wilks et al. (1976) studied MHD free convection about a semiinfinite vertical plate in a strong cross field. Takhar and Soundalgekar (1980) investigated dissipation effects on MHD free convection flow past a semi-infinite vertical plate. Hossain (1992) studied viscous and Joule heating effects on MHD free convection flow with variable plate temperature. Aldoss et al. (1996) analyzed MHD mixed convection from a horizontal circular cylinder. El-Amin (2003) found out the combined effect of viscous dissipation and Joule heating on MHD forced convection over a non-isothermal horizontal circular cylinder embedded in a fluid saturated porous medium. $\mathrm{He}$ observed that both the velocity profiles and temperature profiles shifted down for increasing value of magnetic parameter and that are rise up for increasing value of joule heating parameter. Recently, Molla et al. (2012) studied the effect of temperature dependent viscosity on MHD natural convection flow from an isothermal sphere.

However, the joule heating effects on MHD natural convection flow in presence of pressure stress work and viscous dissipation has received little attention. Hence, the present study is attempted.

\section{Mathematical AnAlysis}

Let us consider a steady natural convection flow of a viscous incompressible fluid from an isothermal horizontal circular cylinder of radius a placed in a fluid of uniform temperature. A uniform magnetic field having strength $B_{0}$ is acting normal to the cylinder surface. The effects of pressure stress work, viscous dissipation and joule heating in the flow region and conduction from surface considered in the present study. The flow configuration and the coordinates system are shown in Fig.1. Under the balance laws of mass, momentum and energy and with the help of Boussinesq approximation for the body force term in the momentum equation, the equations governing this boundary-layer natural convection flow can be written as:

\section{Continuity equation}

$\frac{\partial \bar{u}}{\partial \bar{x}}+\frac{\partial \bar{v}}{\partial \bar{y}}=0$

Momentum equation

$$
\begin{gathered}
\bar{u} \frac{\partial \bar{u}}{\partial \bar{x}}+\bar{v} \frac{\partial \bar{u}}{\partial \bar{y}}= \\
v \frac{\partial^{2} \bar{u}}{\partial \bar{y}^{2}}+g \beta\left(T-T_{\infty}\right) \sin \left(\frac{\bar{x}}{a}\right)- \\
\frac{\sigma B_{0}^{2} \bar{u}}{\rho}
\end{gathered}
$$

Energy equation

$$
\begin{aligned}
\bar{u} \frac{\partial T}{\partial \bar{x}}+\bar{v} \frac{\partial T}{\partial \bar{y}}= & \frac{K}{\rho C_{P}} \frac{\partial^{2} T}{\partial \bar{y}^{2}}+\frac{\mu}{\rho C_{P}}\left(\frac{\partial \bar{u}}{\partial \bar{y}}\right)^{2}+ \\
& \frac{T \beta}{\rho C_{P}} \bar{u} \frac{\partial P}{\partial \bar{x}}+\frac{\sigma B_{0}{ }^{2} \bar{u}^{2}}{\rho}
\end{aligned}
$$

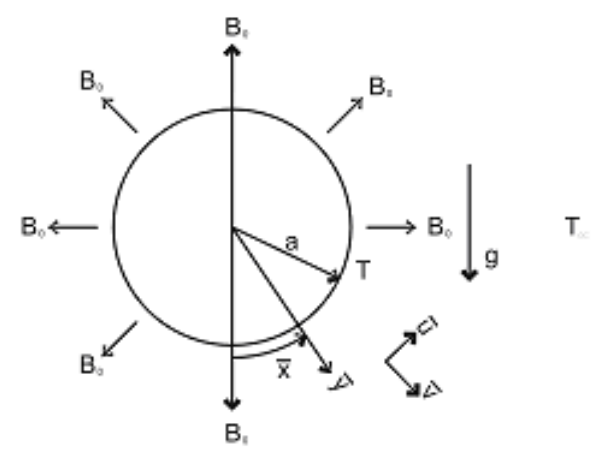

Fig. 1. The geometry of the problem

The physical situation of the system suggests the following boundary conditions

$$
\left.\begin{array}{l}
\bar{u}=\bar{v}=0, T=T_{w} \text { at } \bar{y}=0, x>0 \\
\bar{u} \rightarrow 0, T \rightarrow T_{\infty} \text { as } \bar{y} \rightarrow \infty
\end{array}\right\}
$$

The governing equations and the boundary conditions Eqs. (1)-(4) can be made non-dimensional, using the Grashof number $G r=\frac{g \beta a^{3}\left(T_{w}-T_{\infty}\right)}{v^{2}}$ which is assumed large and the following non-dimensional variables:

$$
\left.\begin{array}{l}
x=\frac{\bar{x}}{a}, y=\frac{\bar{y}}{a} G r^{\frac{1}{4}}, u=\frac{\bar{u} a}{v} G r^{-\frac{1}{2}}, \\
v=\frac{\bar{v} a}{v} G r^{-\frac{1}{4}}, \theta=\frac{T-T_{\infty}}{T_{w}-T_{\infty}}
\end{array}\right\}
$$

Where $\theta$ is the dimensionless temperature. The non dimensional forms of the Eqs. (1)-(3) are as follows:

$$
\frac{\partial u}{\partial x}+\frac{\partial v}{\partial y}=0
$$


$u \frac{\partial u}{\partial x}+v \frac{\partial u}{\partial y}+M u=\frac{\partial^{2} u}{\partial y^{2}}+\theta \sin x$

$u \frac{\partial \theta}{\partial x}+v \frac{\partial \theta}{\partial y}=\frac{1}{\operatorname{Pr}} \frac{\partial^{2} \theta}{\partial y^{2}}-\frac{g \beta a}{c_{P}}\left\{\frac{T_{\infty}+\theta\left(T_{W}-T_{\infty}\right)}{T_{W}-T_{\infty}}\right\} u+J u^{2}$

Where $\quad M=\left(\sigma a^{2} B_{0}^{2}\right) /\left(v \rho G r^{1 / 2}\right)$ is the magnetic parameter, $J=\left(\sigma v B_{0}{ }^{2} G r^{1 / 2}\right) /\left\{\rho c_{p}\left(T_{w}-T_{\infty}\right)\right\}$ is the joule heating parameter and $P r=\mu c_{p} / \kappa$ is the Prandtl number.

The boundary condition Eq. (4) can be written as in the following dimensionless form:

$$
u=v=0, \theta=1 \text { at } y=0
$$$$
u \rightarrow 0, \theta \rightarrow 0 \text { as } y \rightarrow \infty \text {, }
$$

To solve Eqs. (6)-(8), subject to the boundary condition Eq. (9), we assume following transformations

$$
\psi=x f(x, y), \theta=\theta(x, y)
$$

Where $\psi$ is the stream function usually defined as

$$
u=\partial \psi / \partial y, v=-\partial \psi / \partial x
$$

Substituting Eq. (11) into the Eqs. (6)-(9), the new forms of the dimensionless Eq. (7) and Eq. (8) are

$$
\begin{aligned}
& f^{\prime \prime \prime}+f f^{\prime \prime}-f^{\prime 2}-M f^{\prime}+\theta \frac{\sin x}{x}=x\left(f^{\prime} \frac{\partial f^{\prime}}{\partial x}-f^{\prime \prime} \frac{\partial f}{\partial x}\right) \\
& \frac{1}{\operatorname{Pr}} \theta^{\prime \prime}+f \theta^{\prime}+\lambda x^{2} f^{\prime \prime 2}-\varepsilon x f^{\prime}\left[\frac{T_{\infty}}{T_{W}-T_{\infty}}\right]-\varepsilon \theta f^{\prime} \\
& +J x^{2} f^{\prime 2}=x\left(f^{\prime} \frac{\partial \theta}{\partial x}-\theta^{\prime} \frac{\partial f}{\partial x}\right)
\end{aligned}
$$

In the above equations primes denote differentiation with respect to $y$. The corresponding boundary conditions take the following form:

$$
\left.\begin{array}{l}
f(x, 0)=f^{\prime}(x, 0)=0, \theta=1 \text { at } y=0 \\
f^{\prime}(x, \infty) \rightarrow 0, \theta^{\prime}(x, \infty) \rightarrow 0 \text { as } y \rightarrow \infty
\end{array}\right\}
$$

\section{METHOD OF SOLUTION}

Equations (12) and (13) are solved numerically based on the boundary conditions as described in Eq. (14) using one of the most efficient and accurate methods known as implicit finite difference method with Keller box scheme.

\section{ReSUlt AND DiscuSSION}

Joule heating effects on magneto-hydrodynamic natural convection flow in presence of pressure stress work and viscous dissipation from a horizontal circular cylinder has been investigated. The velocity profiles, temperature distributions, local skin-friction and the local rate of heat transfer obtained by the finite difference method for various values of the governing parameters. The aims of the figures are to display how the profiles vary with the scaled stream wise coordinate.

From Fig. 2(a), it is observed that the velocity increases as the values of the joule heating parameter $\mathbf{J}$ increase. The velocity increases significantly along $y$ and becomes maximum and then decreases slowly and finally approaches to zero, the asymptotic value. The maximum values of the velocity are 0.32931258 , $0.33958319,0.35539332$ and 0.36033431 for $\mathbf{J}=0.1$, $0.3,0.5$ and 0.9 respectively which occur at $y=1.80$ for first, second maximum values, at $y=1.45$ for third and fourth maximum values. Here it is observed that the velocity increase by $15.23 \%$ as $\mathrm{J}$ increases from 0.1 to 0.9. From Fig. 2(b), it is seen that when the values of joule heating parameter $\mathrm{J}$ increase, the temperature also increases.

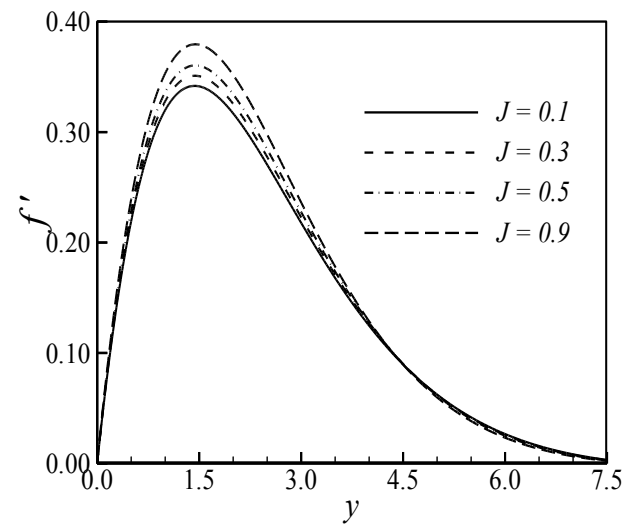

Fig. 2(a). Variation of velocity profile against $y$ for varying of $J$ with $M=0.1, \lambda=0.5, \varepsilon=0.5$ and $P r$ $=1.0$.

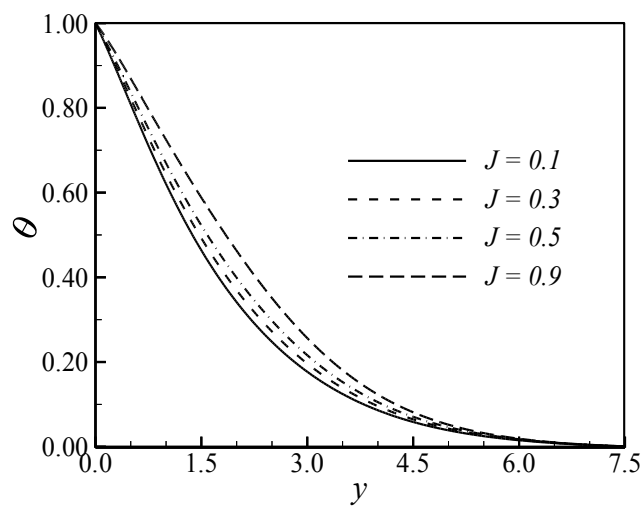

Fig. 2(b). Variation of temperature against y for varying of $\mathrm{J}$ with $\mathrm{M}=0.1, \lambda=0.5, \varepsilon=0.5$ and $\operatorname{Pr}=1.0$.

Fig. 3(a) and Fig. 3(b) display results for the velocity and temperature profiles for different values of magnetic parameter $\mathrm{M}(\mathrm{M}=0.1,0.3,0.5,0.9)$ having Prandtl number $\operatorname{Pr}=1.0, \mathrm{~J}=0.1 \lambda=0.5, \varepsilon=0.5$. It is observed that, as the magnetic parameter $\mathrm{M}$ increases, the velocity profile decreases between $0 \leq y \leq 5$ and then increases with very small difference and finally approaches to zero along y direction. The temperature 
profile increases with increasing magnetic parameter $\mathrm{M}$. The maximum values of the velocity are recorded as $0.36033401,0.32258730,0.29037867$ and 0.263928080 for $\mathrm{M}=0.1,0.3,0.5$ and 0.9 respectively which occur at $\mathrm{y}=1.43$ for $1 \mathrm{st}, 2 \mathrm{nd}, 3 \mathrm{rd}$ and 4 th maximum values. It is found that the velocity decreases by $26.75 \%$ as the magnetic parameter $\mathrm{M}$ increases from 0.1 to 0.9 .

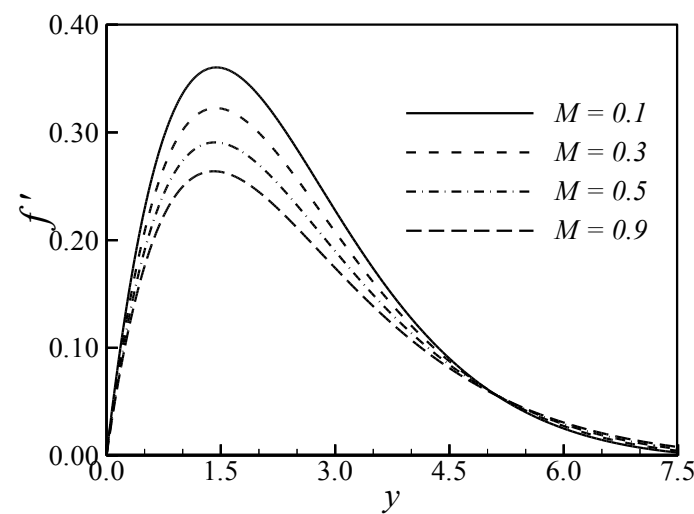

Fig. 3(a). Variation of velocity profile against y for varying of $M$ with $J=0.1, \lambda=0.5, \varepsilon=0.5$ and $\operatorname{Pr}=1.0$.

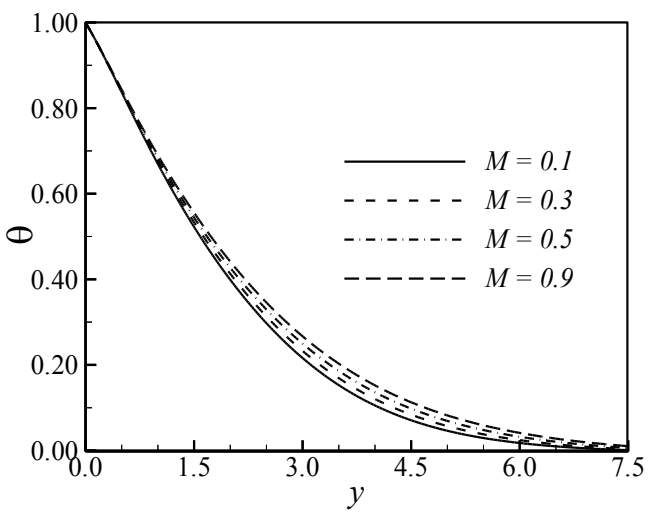

Fig. 3(b). Variation of temperature against y for varying of $\mathrm{M}$ with $\mathrm{J}=0.1, \lambda=0.5, \varepsilon=0.5$ and $\operatorname{Pr}=1.0$.

Figures 4(a) and 4(b) indicate the effects of the Prandtl number $\operatorname{Pr}$ with $\mathrm{M}=0.1, \lambda=0.5 \mathrm{~J}=0.1$ and $\varepsilon=0.5$ on the velocity profiles and the temperature profiles. From Fig. 4(a) it is observed that the increasing values of Prandtl number Pr leads to the decrease in the velocity profiles. The maximum values of the velocity are $0.34181852,0.31031986,0.27675142$ and 0.26104378 for $\operatorname{Pr}=0.72,1.0,1.44$ and 1.74 respectively which occur at $\mathrm{y}=1.43, \mathrm{y}=1.36, \mathrm{y}=1.30$ and $\mathrm{y}=1.26$ for the first, second, third and fourth maximum value. Here it is depicted that the velocity decreases by $23.63 \%$ as $\operatorname{Pr}$ increases from 0.72 to 1.74 . From Fig. 4(b) it is observed that the temperature profiles decreases with the increasing values of Prandtl number Pr.

It can easily be seen that the effect of the magnetic parameter $\mathrm{M}$ leads to a decrease in the local skin friction coefficient $C f_{x}$ and the local Nusselt number $N u_{x}$ in Fig. 5(a) and Fig. 5(b). This phenomenon can easily be understood from the fact that the magnetic parameter M opposes the flow, therefore decreases the velocity gradient and hence the local skin friction coefficient $C f_{x}$ decreases. Owing to increasing values of $\mathrm{M}$ in the presence of viscous dissipation and pressure stress work, the fluid temperature within the boundary layer increases and the associate thermal boundary layer becomes thicker. For increasing fluid temperature, the temperature difference between fluid and surface decreases and the corresponding rate of heat transfer decreases.

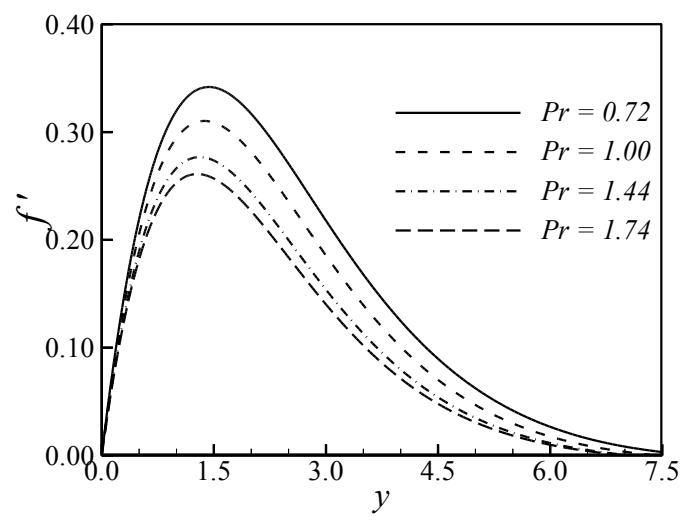

Fig. 4(a). Variation of velocity profile against $y$ for varying of $\operatorname{Pr}$ with $M=0.1, \lambda=0.5, \varepsilon=0.5$ and $J=0.1$.

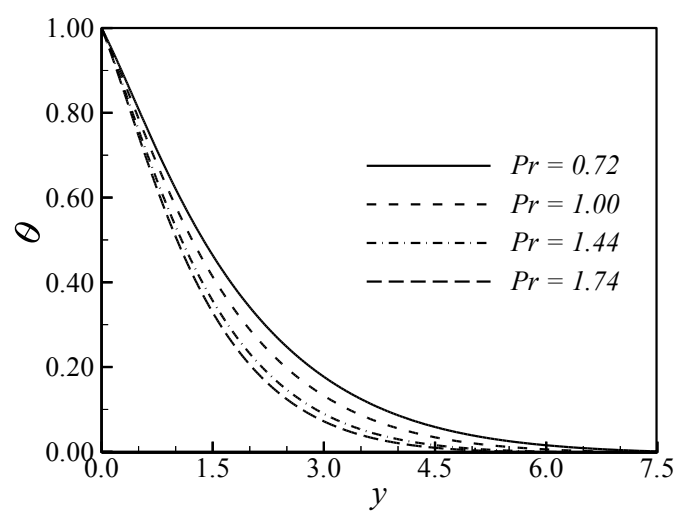

Fig. 4(b). Variation of temperature profile against $y$ for varying of $\operatorname{Pr}$ with $M=0.1, \lambda=0.5, \varepsilon=0.5$ and $J=0.1$.

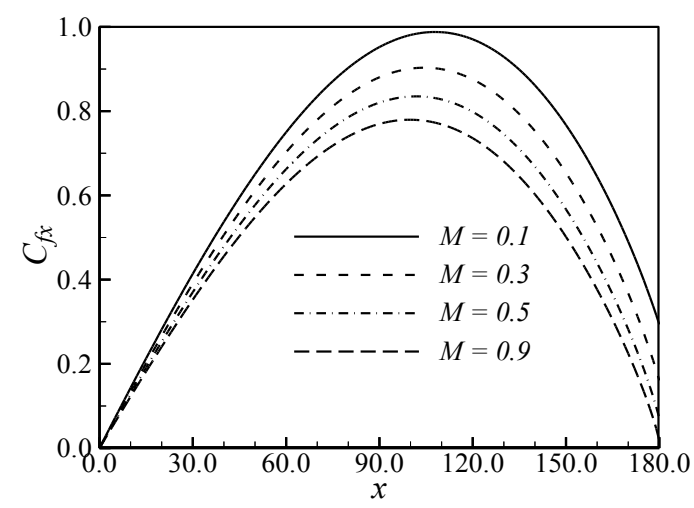

Fig. 5(a). Variation of skin friction against $x$ for varying of $M$ with $J=0.1, \lambda=0.5, \varepsilon=0.5$ and $P r=1.0$. 


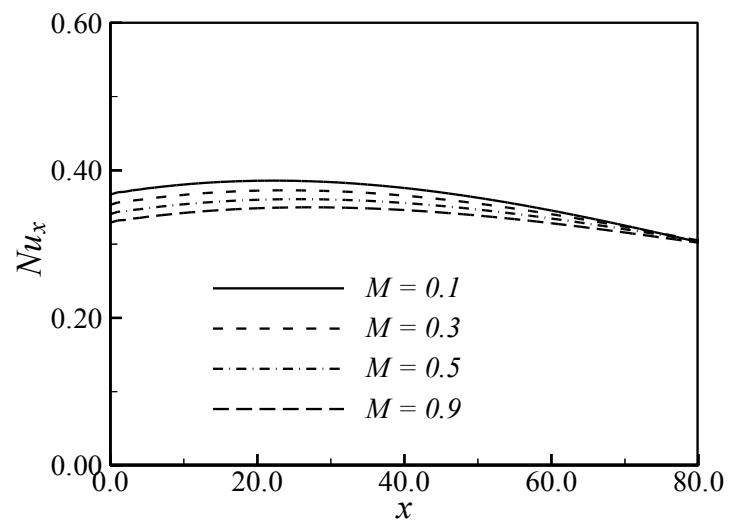

Fig. 5(b). Variation of heat transfer against $\mathrm{x}$ for varying of $M$ with $J=0.1, \lambda=0.5, \varepsilon=0.5$ and $\operatorname{Pr}=1.0$.

The variation of the reduced local skin friction coefficient and the local rate of heat transfer for different values of the joule heating parameter $\mathrm{J}(\mathrm{J}=$ $0.1,0.3,0.5,0.9)$ are illustrated in Fig. 6(a) and Fig. 6(b) with $\mathrm{M}=0.1, \lambda=0.5$ and $\varepsilon=0.5$ and Prandtl number $\operatorname{Pr}=1.0$. From the figures it can be seen that the increase of the joule heating parameter $\mathrm{J}$ leads to an increase in the local skin-friction coefficient $C f_{x}$ and a decrease in the local Nusselt number $N u_{x}$. These are expected, since the joule heating mechanism in presence of viscous dissipation and pressure stress work creates a layer of hot fluid near the surface, and finally the resultant temperature of the fluid exceeds the surface temperature. For this reason the rate of heat transfer from the surface decreases. Owing to the enhanced temperature, the viscosity of the fluid increases and the corresponding local skin-friction coefficient increases.

In order to verify the accuracy of the present work, the numerical values of the local Nusselt number $N u_{x}$ for $\mathrm{M}=0.0, \mathrm{~J}=0.0, \lambda=0.0, \varepsilon=0.0$ and $\operatorname{Pr}=1.00$ in different position of $\mathrm{x}$ are compared with those reported by Merkin (1976), Nazar et al. (2002) and Hye et al. (2007) as presented in table 1 The results are found to be in excellent agreement.

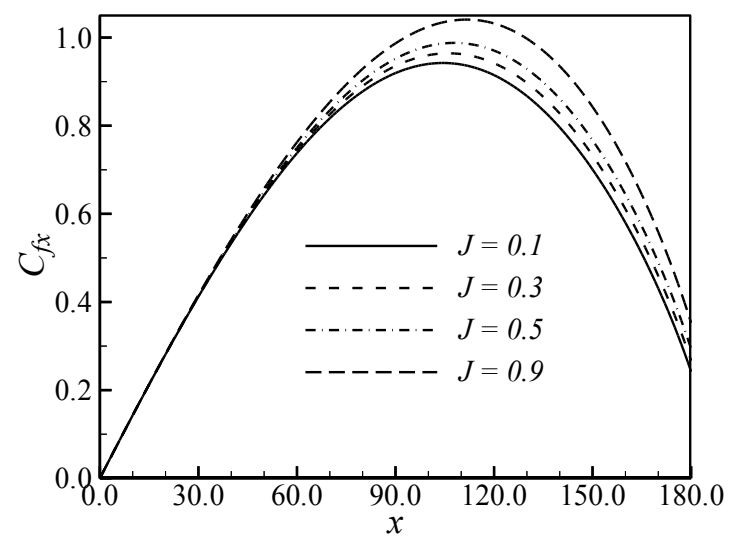

Fig. 6(a). Variation of skin friction against $\mathrm{x}$ for varying of $J$ with $M=0.1, \lambda=0.5, \varepsilon=0.5$ and

$$
\operatorname{Pr}=1.0
$$

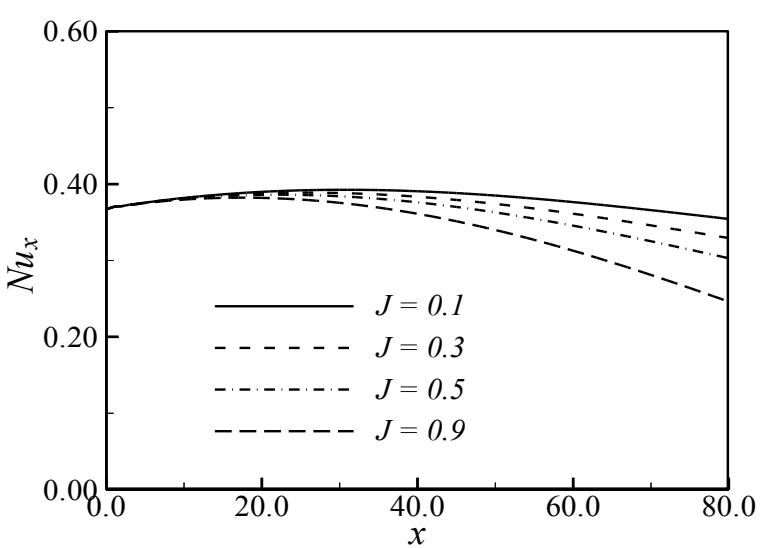

Fig. 6(b). Variation of heat transfer against $\mathrm{x}$ for varying of $J$ with $M=0.1, \lambda=0.5, \varepsilon=0.5$ and $\operatorname{Pr}=1.0$

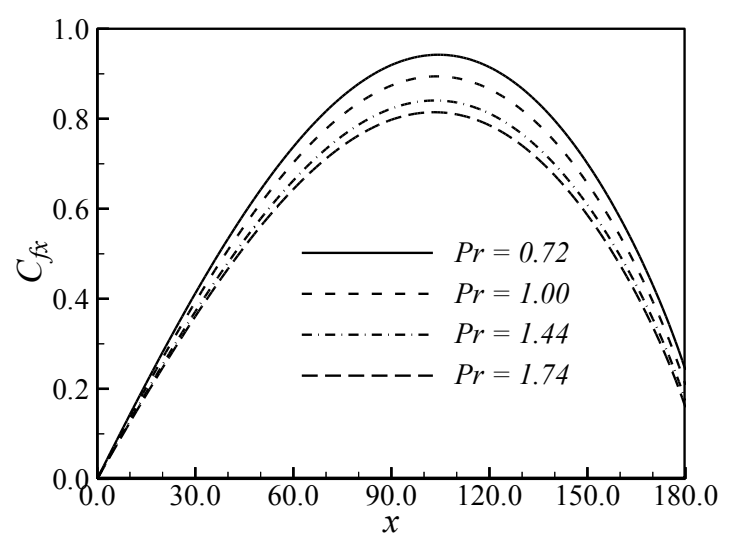

Fig. 7(a). Variation of skin friction against $\mathrm{x}$ for varying of $\operatorname{Pr}$ with $\mathrm{M}=0.1, \lambda=0.5, \varepsilon=0.5$ and $\mathrm{J}=0.1$

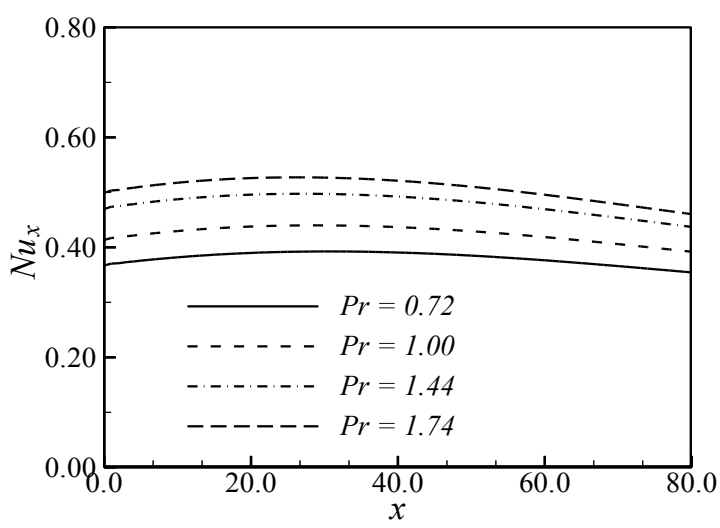

Fig.7(b). Variation of heat transfer against $\mathrm{x}$ for varying of $\operatorname{Pr}$ with $\mathrm{M}=0.1, \lambda=0.5, \varepsilon=0.5$, and $\mathrm{J}=0.1$ 
Table 1 Numerical values of $N u_{x}$ for different values of $x$ while $\operatorname{Pr}=1.0, M=0.0, J=0.0, \lambda=0.0$ and $\varepsilon=0.0$

\begin{tabular}{|c|c|c|c|c|}
\hline$x$ & $\begin{array}{c}\text { Merkin } \\
(1976)\end{array}$ & $\begin{array}{c}\text { Nazar } \text { et al. } \\
(2002)\end{array}$ & $\begin{array}{c}\text { Hye } \text { et al. } \\
(2007)\end{array}$ & Present \\
\hline 0.0 & 0.4214 & 0.4214 & 0.4241 & 0.4216 \\
\hline$\pi / 6$ & 0.4161 & 0.4161 & 0.4161 & 0.4163 \\
\hline$\pi / 3$ & 0.4007 & 0.4005 & 0.4005 & 0.4006 \\
\hline$\pi / 2$ & 0.3745 & 0.3741 & 0.3741 & 0.3741 \\
\hline $2 \pi / 3$ & 0.3364 & 0.3355 & 0.3355 & 0.3355 \\
\hline $5 \pi / 6$ & 0.2825 & 0.2811 & 0.2811 & 0.2811 \\
\hline$\pi$ & 0.1945 & 0.1916 & 0.1916 & 0.1912 \\
\hline
\end{tabular}

\section{Conclusion}

We have studied the joule heating effects on magnetohydrodynamic (MHD) natural convection flow in presence of viscous dissipation and pressure stress work from a horizontal circular cylinder. The transformed non-similar boundary layer governing equations of the flow together with the boundary conditions were solved numerically using implicit finite difference method together with Keller box scheme. The coupled effect of natural convection that the temperature and the rate of heat transfer is continuous at the surface. From the present investigation, the following conclusions may be drawn:

- The local skin friction coefficients and the rate of heat transfer along the surface of the cylinder decrease for the increasing value of magnetic parameter $\mathrm{M}$.

- An increase in values of M leads to decrease the velocity distribution but slightly increase the temperature distribution.

- For increasing values of joule heating parameter J, the skin-friction coefficient increases but the Nusselt number decreases significantly within the boundary layer.

- With the effect of joule heating parameter J, both the velocity and temperature distributions increase significantly the thickness of the thermal boundary layer.

- An increasing value of Prandtl number Pr leads to decrease in the velocity and the temperature distributions as expected.

\section{REFERENCES}

Ackroyd, J. A. D. (1974). Stress work effets in laminar flat-plate natural convection. J. of Fluid Mech., 62, 677-695.

Alam, M., A. Alim and M.K. Chowdhury (2006). Effect of pressure stress work and viscous dissipation flow along a vertical flat plate with heat conduction. Journal of Naval Architecture and Marine Engineering, 3(2), 69- 76.

Aldoss, T.K., Y.D. Ali and M.A. Al-Nimr (1996). MHD mixed convection from a horizontal circular cylinder. Numerical Heat Transfer, Part A, 30, 379-396.
Cebeci, T. and P. Bradshaw (1984). Physical and computational aspects of convective heat transfer, Springer, New York.

El-Amin, M.F. (2003). Combined effect of viscous dissipation and Joule heating on MHD forced convection over a non-isothermal horizontal cylinder embedded in a fluid saturated porous medium. Journal of Magnetism and Magnetic materials, 263, 337-343.

Gebhart, B. (1962). Effect of dissipation in natural convection $J$ of Fluid Mech., 14, 225-232.

Hye, M.A, M.M. Molla and M.H. Khan (2007). Conjugate effects of heat and mass transfer on natural convection flow across an isothermal horizontal circular cylinder with chemical reaction. Int. J. of Non-linear modeling and control, 12, 191-201.

Hossain, M. A. (1992). Viscous and Joule heating effects on MHD-free convection flow with variable plate temperature. Int. J. heat Mass Transfer, 35, 3485-3487.

Joshi, Y. and B. Gebhart(1981). Effect of pressure stress work and viscous dissipation in some natural convection flows. Int. J. of Heat Mass Transfer, 24, 1377-1388.

Keller, H.B. (1978). Numerical methods in the boundary layer theory. Annual Reviews of Fluid Mechanics, 10, 417-433.

Kuehn, T.H. and R.J. Goldstein (1980). Numerical solution to the Navier-Stokes equations for laminar natural convection about a horizontal isothermal circular cylinder. Int. J. heat Mass Transfer, 23, 971-979.

Merkin, J. H. and I. Pop (1988). A note on the free convection boundary layer on a horizontal circular cylinder with constant heat flux. Wärme und Stoffübertragung, 22, 79-81.

Sparrow, E.M. and R.D. Cess (1961). Effect of magnetic field on free convection heat transfer. Int. $J$ of Heat and Mass Transfer, 3, 267-274.

Takhar, H.S. and V.M. Soundalgekar (1980). Dissipation effects on MHD free convection flow past a semi-infinite vertical plate. Applied Science Research, 36, 163-171. 
A. S. Bhuiyan et al. / JAFM, Vol. 7, No. 1, pp. 7-13, 2014.

Wang, P., R. Kahawita and T.H. Nguyen (1990). Numerical computation of natural convection flow about a horizontal cylinder Using Splines. Numerical Heat Transfer, Part-A., 17, 191-215.

Wilks, G. (1976). Magnetohydrodynamics free convection about a semi-infinite vertical plate in a strong cross field ZAMP, 27, 621-631.
Zakerullah (1972). Viscous dissipation and pressure work effects in axisymmetric natural convection flows. J. Bangladesh Math. Soc., 2, 43.

Molla, M.M., S.C. Saha and M.A. Hossain (2012). The Effect of Temperature Dependent Viscosity on MHD Natural Convection Flow from an Isothermal Sphere. Journal of Applied Fluid Mechanics, 5(2), 25-31. 